\title{
Phosphoenolpyruvic Acid, an Intermediary Metabolite of Glycolysis, as a Potential Cytoprotectant and Anti-oxidant in HeLa Cells
}

\author{
Yuki Kondo, ${ }^{a, \#}$ Yoichi Ishitsuka, ${ }^{* a,{ }^{a}}$ Daisuke Kadowaki, ${ }^{b, c}$ Masataka Kuroda,${ }^{a}$ Yuta Tanaka, ${ }^{a}$ \\ Minako Nagatome, ${ }^{a}$ Mitsuru Irikura, ${ }^{a}$ Sumio Hirata, ${ }^{c}$ Keizo Sato, ${ }^{d}$ Toru Maruyama, ${ }^{b, c}$ \\ Naotaka Hamasaki, ${ }^{e}$ and Tetsumi Irie ${ }^{a, c}$ \\ ${ }^{a}$ Department of Clinical Chemistry and Informatics, Graduate School of Pharmaceutical Sciences, Kumamoto \\ University; ${ }^{b}$ Department of Biopharmaceutics, Graduate School of Pharmaceutical Sciences, Kumamoto University; \\ ${ }^{c}$ Center for Clinical Pharmaceutical Sciences, Faculty of Pharmaceutical Sciences, Kumamoto University; 5-1 \\ Oe-honmachi, Kumamoto 862-0973, Japan: ${ }^{d}$ First department of Biochemistry, School of Pharmaceutical Sciences, \\ Kyushu University of Health and Welfare; 1714-1 Yoshino, Nobeoka, Miyazaki 882-8508, Japan: and ${ }^{e}$ Department of \\ Clinical Chemistry and Laboratory Medicine, Nagasaki International University; Sasebo 859-3298, Japan. \\ Received September 22, 2011; accepted December 27, 2011; published online January 16, 2012
}

This study examined the cytoprotective and anti-oxidative properties of phosphoenolpyruvic acid (PEP), a glycolysis metabolite with a high-energy phosphate group. PEP (0.1-10 mM) significantly attenuated the decrease in cell viability induced by hydrogen peroxide $\left(\mathrm{H}_{2} \mathrm{O}_{2}\right)$ in HeLa cells in a dose-dependent manner. PEP also inhibited the decrease in calcein-acetomethoxy-stained cells and the increase in propidium iodidestained cells that were induced by $\mathrm{H}_{2} \mathrm{O}_{2}$. The $\mathrm{H}_{2} \mathrm{O}_{2}$-stimulated increase in intracellular reactive oxygen species was significantly reduced by PEP. PEP also demonstrated scavenging potential against hydroxyl radicals, as assessed by the electron paramagnetic resonance method. In addition, PEP demonstrated scavenging potential against the 1,1-diphenyl-2-picrylhydrazyl radical, a representative artificial radical, although the potential is very weak. PEP (10 mM) slightly inhibited the decrease in cellular ATP content induced by $\mathrm{H}_{2} \mathrm{O}_{2}$, but did not show any effects at low doses $(0.1,1 \mathrm{~mm})$. PEP $(0.1-10 \mathrm{~mm})$ also attenuated the cell injury but not the decrease in intracellular ATP content, induced by 2-deoxy-D-glucose, a glycolysis inhibitor. These results indicate that PEP exerts cytoprotective effects and has anti-oxidative potential, although the precise cytoprotective mechanisms are not fully elucidated. We suggest that PEP is a functional carbohydrate metabolite with cytoprotective and anti-oxidative activity, and is potentially useful as a therapeutic agent against diseases that involve the oxidative stress.

Key words phosphoenolpyruvic acid; anti-oxidant; oxidative stress; cellular injury; hydrogen peroxide

Phosphoenolpyruvic acid (PEP) is a high-energy intermediate substance in the glycolytic and gluconeogenic pathways. PEP can penetrate the cell membrane and transfer its highenergy phosphate group to adenosine diphosphate, aiding the replenishment of intracellular ATP., ${ }^{1,2}$ It has been reported that PEP improved post-ischemic energy status in the heart, ${ }^{3)}$ skeletal muscle, ${ }^{4}$ and liver ${ }^{1)}$ in rats. Hojo et al..$^{5)}$ demonstrated that transplanted kidney function and graft survival were improved by PEP in experimental kidney transplantation in a canine model. In addition, we demonstrated that PEP attenuated pulmonary gas exchange dysfunction and pulmonary vascular hyperpermeability in acute lung injury induced by oleic acid in the guinea pig, a model of acute lung injury. ${ }^{6}$ These findings indicate that PEP is an attractive prospect as a putative agent that protects cells and organs from damage by improving their energy status. However, the mechanism(s) of its protective effects have not been well defined.

Reactive oxygen species (ROS) such as hydrogen peroxide $\left(\mathrm{H}_{2} \mathrm{O}_{2}\right)$ and the hydroxyl radical $(\cdot \mathrm{OH})$ are highly reactive substances that play important roles in some physiological conditions. However, they also contribute to pathophysiological damage as inducers of oxidative stress. ${ }^{7-10)}$ Oxidative stress seems to be a potent factor in the development of organ ischemia/reperfusion injuries ${ }^{11)}$ and of acute lung injury induced by oleic acid. ${ }^{12,13)}$ From this evidence grew the hypothesis that the protection afforded by PEP in animal models of these

\# These authors contributed equally to this work. disorders was due to it counteracting the effects of ROS. This study was conducted to examine whether PEP was able to exert anti-oxidative activity and attenuate cell injury induced by oxidative stress. We examined the effects of PEP on cell injury and intracellular ROS generation induced by $\mathrm{H}_{2} \mathrm{O}_{2}$ in HeLa cells. To evaluate the anti-oxidative potential of PEP, we measured its ability to scavenge $\cdot \mathrm{OH}$ and the 1,1-diphenyl2-picrylhydrazyl (DPPH) radical, a representative artificial radical that is often used to determine the radical-scavenging activity of a test compound. In addition, we used HeLa cells to investigate whether energy supplementation was a potential mode of action of PEP by measuring the effect of PEP on the decrease in intracellular ATP levels induced by $\mathrm{H}_{2} \mathrm{O}_{2}$ and the cell injury induced by 2-deoxy-D-glucose (2-DG), a glycolytic ATP production inhibitor.

\section{MATERIALS AND METHODS}

Materials Sodium phosphoenolpyruvate monohydrate was kindly donated by Ube Kousan (Yamaguchi, Japan). $\mathrm{H}_{2} \mathrm{O}_{2}$ and 2-DG were purchased from Wako Pure Chemicals (Osaka, Japan). The cell counting kit and Cellstain ${ }^{\circledR}$ Double Staining Kit were obtained from Dojindo Laboratories (Kumamoto, Japan). 5- (and 6)-Chloromethyl$2^{\prime} 7^{\prime}$-dichlorodihydrofluorescein diacetate acetyl ester (CM$\mathrm{H}_{2}$ DCFDA) was obtained from Invitrogen (Carlsbad, CA, U.S.A.). ATP Bioluminescent assay kit and Minimum essential medium (MEM) were obtained from Sigma (St. Louis, 
MO, U.S.A.). 5,5-Dimethyl-1-pyrroline $N$-oxide (DMPO) was obtained from Enzo Life Sciences (Farmingdale, NY, U.S.A.). DPPH radical was obtained from Nacalai Tesque, Inc. (Kyoto, Japan). HyClone ${ }^{\mathrm{TM}}$ fetal bovine serum (FBS) was purchased from Thermo Scientific (Logan, UT, U.S.A.). All other reagents and solvents were of reagent grade. De-ionized and distilled bio-pure grade water was used throughout the study.

Cell Culture The HeLa cell line was obtained from RIKEN BioResource Center Cell Bank (Ibaraki, Japan). HeLa cells were cultured at $37^{\circ} \mathrm{C} / 5 \% \mathrm{CO}_{2}$ in $\mathrm{MEM}$ supplemented with $10 \% \mathrm{FBS}, 100 \mathrm{IU} / \mathrm{mL}$ of penicillin, $100 \mu \mathrm{g} / \mathrm{mL}$ streptomycin. Confluent cultures were washed with phosphate-buffered saline (PBS) pH 7.4, detached with ethylene diaminetetraacetic acid (EDTA) and trypsin, centrifuged and sub-cultured in 96-well plates or $60 \mathrm{~mm}$ dishes. Cells were seeded and grown on culture dishes for $24 \mathrm{~h}$ before use either in the cell viability assay or in the measurement of intracellular ATP.

Cell Viability and Cell Death Assays The cell injury induced by $\mathrm{H}_{2} \mathrm{O}_{2}$ was evaluated by a cell viability assay, involving mitochondrial dehydrogenase activity, and by the calcein-acetomethoxy (Calcein-AM) and propidium iodide (PI) (which stain viable and dead cells, respectively) dual-staining assay. The mitochondrial dehydrogenase activity was measured using a modified 3-(4,5-dimethylthiazol2-yl)-2,5-diphenyltetrazolium bromide (MTT) assay, namely the water-soluble tetrazolium salt (WST-1) assay and the Cell Counting Kit according to the manufacturer's protocol. Cells were incubated at $37^{\circ} \mathrm{C} / 5 \% \quad \mathrm{CO}_{2}$ in FBS-containing MEM with or without $\mathrm{H}_{2} \mathrm{O}_{2}$ and the cell viability was assessed after 24h. Calcein-AM/PI co-staining was performed using the Cellstain ${ }^{\circledR}$ Double Staining Kit. HeLa cells, seeded at a density of $1 \times 10^{4}$ cells/well in a 96 well plate, were treated with $\mathrm{H}_{2} \mathrm{O}_{2}(0.1 \mathrm{mM})$ and PEP at different concentrations $(0-10 \mathrm{~mm})$ for $24 \mathrm{~h}$ and then incubated with $2 \mu \mathrm{M}$ Calcein-AM and $4 \mu \mathrm{M}$ PI in PBS for $15 \mathrm{~min}$. Cell death was observed by measuring the fluorescence of Calcein-AM and PI at excitation/emission wavelengths of $490 / 510 \mathrm{~nm}$ and $530 / 580 \mathrm{~nm}$, respectively, using a fluorescent microscope (Biorevo; Keyence Co., Osaka, Japan). Having defined the non-cytotoxic dose in HeLa cells as being less than $20 \mathrm{~mm}$ (data not shown), PEP was only used at concentrations up to $10 \mathrm{~mm}$ in cellular assays.

Measurement of Intracellular ROS Production Intracellular ROS production was assessed using the ROS assay with the $\mathrm{CM}-\mathrm{H}_{2} \mathrm{DCFHDA}$ fluorescence probe. HeLa cells, seeded at a density of $1 \times 10^{4}$ cells/well in a 96 well plate, were incubated with $5 \mu \mathrm{M} \mathrm{CM}-\mathrm{H}_{2}$ DCFDA; in D-PBS(-) for $30 \mathrm{~min}$ and then treated with $\mathrm{H}_{2} \mathrm{O}_{2}(0.1 \mathrm{~mm})$ and PEP at different concentrations $(0-10 \mathrm{~mm})$ for $360 \mathrm{~min}$. The production of ROS was evaluated by the change in fluorescence intensity of CM$\mathrm{H}_{2}$ DCFDA at excitation/emission wavelengths of $485 / 535 \mathrm{~nm}$, respectively, using a fluorescent microplate reader (SpectraFluor; Tecan Co., Ltd., Männedorf, Switzerland).

Measurements of Hydroxy Radical and 1,1-Diphenyl2-picrylhydrazyl Radical To evaluate the anti-oxidative potential of PEP, we measured its ability to scavenge $\cdot \mathrm{OH}$ and the DPPH radical, a representative artificial radical that is often used to determine the radical-scavenging activity of a test compound, in accordance with methods described previously. ${ }^{10)}$ The $\cdot \mathrm{OH}$ was generated using an $\mathrm{H}_{2} \mathrm{O}_{2} / \mathrm{UV}$ (UV) radiation system. $\cdot \mathrm{OH}$ was assayed by electron paramagnetic resonance (EPR) spin-trapping with DMPO, and the scaveng- ing activity was calculated from the relative intensity of the peak for the DMPO-OH EPR signal. The reaction mixture contained $100 \mu \mathrm{M}$ diethylene-triamine-penta acetic acid, $9 \mathrm{~mm}$ DMPO and $500 \mu \mathrm{M} \mathrm{H}_{2} \mathrm{O}_{2}$ in the absence or presence of varying concentrations of PEP. This mixture was immediately transferred to the EPR flat cell and irradiated with UV $(254 \mathrm{~nm})$ for $30 \mathrm{~s}$. EPR spectra were obtained immediately after UV-irradiation and were recorded at room temperature on a JES-TE 200 EPR spectrometer (JEOL, Tokyo, Japan). After recording the EPR spectra, the signal intensities of the DMPO-OH adducts were normalized against that of a manganese oxide $\left(\mathrm{Mn}^{2+}\right)$ signal, in which $\mathrm{Mn}^{2+}$ served as an internal control. An EPR spectrum of DMPO spin adducts of $\cdot \mathrm{OH}$ was generated, and the relative quantification of the anti-oxidant activity of PEP against $\cdot \mathrm{OH}$ was evaluated by DMPO spin adduct intensities of $\cdot \mathrm{OH}$.

Reduction of DPPH (which is naturally a violet color) produces a yellow color that can be measured at $540 \mathrm{~nm}$ wavelength. PEP solution was mixed with $0.16 \mathrm{mM}$ DPPH ethanol solution at a ratio of $1: 1$, and allowed to stand for $30 \mathrm{~min}$ at room temperature in the dark before measuring the absorbance at $540 \mathrm{~nm}$. Low absorbance indicates high radical-scavenging activity. The DPPH radical level was determined by measuring the absorbance at $540 \mathrm{~nm}$ using a microplate reader (Model 680; Bio-Rad Laboratories, Hercules, CA, U.S.A.) and the scavenging activity was estimated by the absorbance relative $(\%)$ to the control group.

Measurement of Intracellular ATP Content Intracellular ATP levels were determined using a chemical luminescence assay kit according to the manufacturer's protocol. The quantity of ATP was calculated by luminometer as $\mathrm{ATP}_{\text {sample }}=\left(1 \times 10^{-6} \times I_{\text {sample }}\right) /($ relative intensity of sample - relative intensity of standard). The living cells were counted by trypan blue dye exclusion test. Each result was expressed as a percentage of intracellular ATP in living cells relative to the $\mathrm{H}_{2} \mathrm{O}_{2}$ - or 2-DG free control.

Effect of PEP on the Decrease in Cell Viability and Intracellular ATP Content Induced by 2-Deoxy-D-glucose To evaluate the effect of PEP on cell injury induced by ATP suppression, we used the glycolysis inhibitor, 2-DG. Cells were incubated at $37^{\circ} \mathrm{C} / 5 \% \mathrm{CO}_{2}$ in $\mathrm{FBS}$-free MEM with or without 2-DG, and cell viability and intracellular ATP content were assessed using a WST-1 assay after $24 \mathrm{~h}$ and chemical luminescence assay after $12 \mathrm{~h}$, respectively. In a preliminary study, we determined the minimum concentrations of 2-DG that induced a decrease in cell viability with high reproducibility, and optimal concentrations were chosen for the experiment. Based on the results, we used 2-DG at a concentration of $5 \mathrm{~mm}$.

Statistical Analysis Results are expressed as mean \pm S.E.M. Statistical analysis was performed using GraphPad Prism ver. 5.01 (GraphPad Software, San Diego, CA, U.S.A.). Multiple comparisons were made using the Tukey (or TukeyKramer) multiple range test.

\section{RESULTS}

Effects of PEP Treatment on the Cell Injury Induced by $\mathrm{H}_{2} \mathrm{O}_{2}$ in HeLa Cells As shown in Fig. 1A, HeLa cells treated with $0.1 \mathrm{mM} \mathrm{H}_{2} \mathrm{O}_{2}$ for $24 \mathrm{~h}$ showed a $69 \%$ decrease in cell viability compared with control $(p<0.01)$, evaluated using 


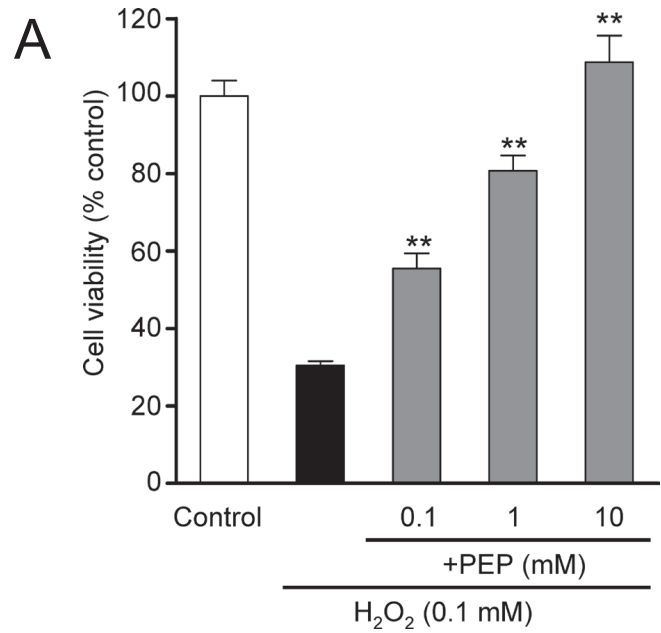

Control

B

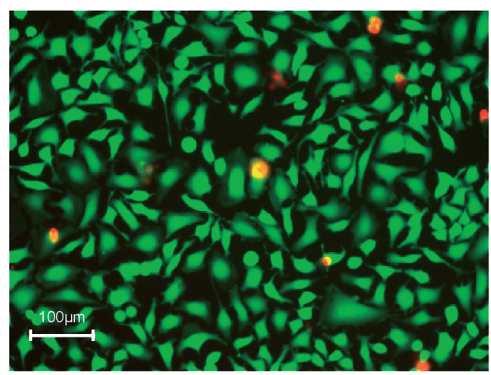

$0.1 \mathrm{mM} \mathrm{H}_{2} \mathrm{O}_{2}$

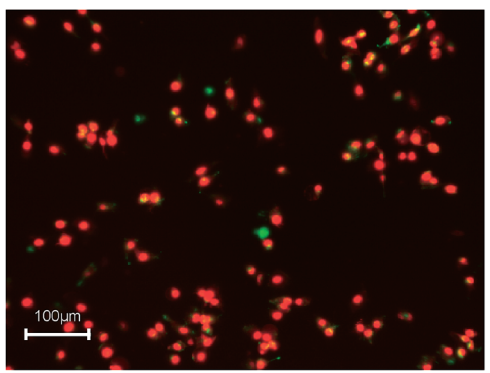

$0.1 \mathrm{mM} \mathrm{H}_{2} \mathrm{O}_{2}$ $+0.1 \mathrm{mM}$ PEP

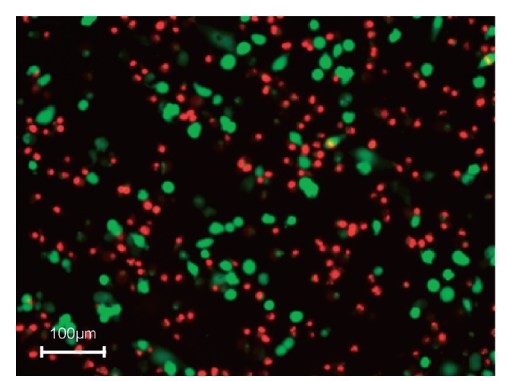

$0.1 \mathrm{mM} \mathrm{H}_{2} \mathrm{O}_{2}$ $+1 \mathrm{mM}$ PEP

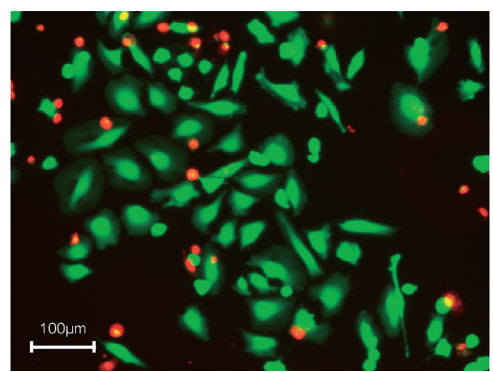

$0.1 \mathrm{mM} \mathrm{H}_{2} \mathrm{O}_{2}$ $+10 \mathrm{mM}$ PEP

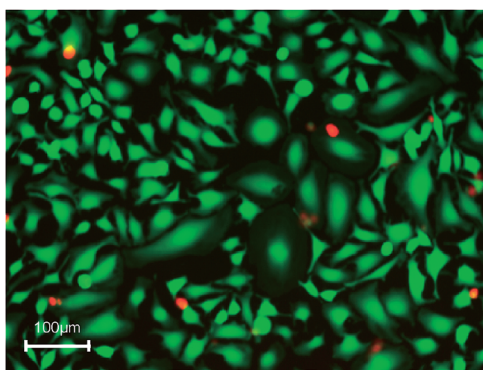

Fig. 1. Effects of PEP on Cell Injury Induced by $\mathrm{H}_{2} \mathrm{O}_{2}$ in HeLa Cells Evaluated by Cell Viability Assay and by Calcein-AM and PI Dual-Staining Assay

(A) Cell viability measured by the WST-1 method. Data are expressed as percent cell survival relative to $\mathrm{H}_{2} \mathrm{O}_{2}$-free control. Each bar represents mean \pm S.E.M. $(n=6-8$ ). Statistical significance is denoted by ** ( $p<0.01$, compared with the $\mathrm{H}_{2} \mathrm{O}_{2}$-treated group). (B) Representative fluorescence microscope pictures of cells stained with calcein-AM (green; viable cells) and PI (red; non-viable cells).

the WST-1 assay. When cells were treated with $0.1-10 \mathrm{~mm}$ PEP (added to the culture medium just after $\mathrm{H}_{2} \mathrm{O}_{2}$ exposure), the decrease in cell viability induced by $\mathrm{H}_{2} \mathrm{O}_{2}$ was significantly and dose-dependently attenuated. In addition, a significant increase in the number of PI-stained cells (red) was observed when treated with $0.1 \mathrm{~mm} \mathrm{H}_{2} \mathrm{O}_{2}$ for $24 \mathrm{~h}$ compared with the vehicle (MEM)-treated control (Fig. 1B). In contrast, when the cells were treated with PEP $(0.1-10 \mathrm{~mm})$ just after $\mathrm{H}_{2} \mathrm{O}_{2}$ exposure, many cells were stained with Calcein-AM (green), indicating an increased number of viable cells.

Effects of PEP Treatment on Intracellular ROS Generation Induced by $\mathrm{H}_{2} \mathrm{O}_{2}$ in HeLa Cells As shown in Fig. 2A, treatment with $0.1 \mathrm{mM} \mathrm{H}_{2} \mathrm{O}_{2}$ significantly increased intracellular ROS generation compared with the control group ( $p<0.05$ at 30 min after $\mathrm{H}_{2} \mathrm{O}_{2}$ exposure; $p<0.01$ at $60-360 \mathrm{~min}$ after exposure). The maximum increase (approximately $210 \%$ of control) was observed at 180 min after $\mathrm{H}_{2} \mathrm{O}_{2}$ treatment. PEP $(0.1-10 \mathrm{~mm})$ significantly inhibited these increases in ROS generation in a dose-dependent manner. In the evaluation of the area under the relative fluorescence intensity-time curve $(A U C)$, significant decreases were observed in $A U C$ in the 1 and $10 \mathrm{~mm}$ PEP groups compared with $\mathrm{H}_{2} \mathrm{O}_{2}$ alone group (Fig. 2B). In addition, $5 \mathrm{~mm} N$-acetyl-L-cysteine (NAC), used as a positive control, also inhibited the increases in ROS generation in this system.

Scavenging Activity of PEP against Hydroxyl and 
A
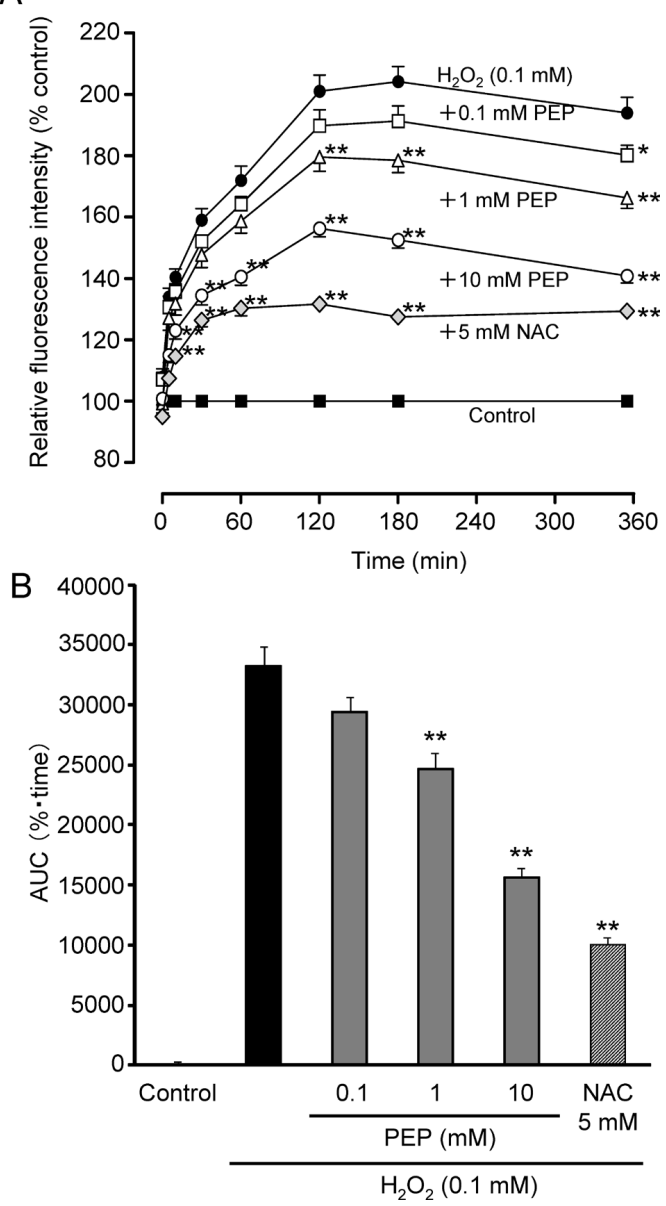

Fig. 2. Effects of PEP on the $\mathrm{H}_{2} \mathrm{O}_{2}$-Induced Increase in Intracellular ROS Production in HeLa Cells, Assessed Using the ROS Assay with the CM- $\mathrm{H}_{2}$ DCFHDA Fluorescence Probe

(A) The time course of the changes in relative fluorescence intensity and (B) the area under the relative fluorescence intensity-time curve. Each point represents mean \pm S.E.M. $(n=8-11)$. Statistical significance is denoted by $*$ or $* *(p<0.05$ or $p<0.01$, respectively, compared with the $\mathrm{H}_{2} \mathrm{O}_{2}$-treated group).

1,1-Diphenyl-2-picrylhydrazyl Radicals Figure 3A shows data for the radical scavenging activity of PEP as measured by EPR. The EPR signals generated by the $\mathrm{H}_{2} \mathrm{O}_{2} / \mathrm{UV}$ radiation system showed typical $\cdot \mathrm{OH}$ signals and were blocked by PEP in a dose-dependent manner. The EPR signals generated by the $\mathrm{H}_{2} \mathrm{O}_{2} / \mathrm{UV}$ radiation system were eliminated by addition of $1 \mathrm{~mm}$ ascorbic acid. PEP (1-100 mM) significantly decreased the production of $\cdot \mathrm{OH}$ when quantitatively evaluated using these spectra (Fig. 3B).

PEP (100 mM) showed a small but statistically significant free radical scavenging effect on the DPPH radical (Fig. 4). Treatment with the positive control $(0.1 \mathrm{~mm}$ ascorbic acid $)$ demonstrated a dramatic scavenging effect on this radical, reducing its levels by approximately $50 \%$.

Effects of PEP on Intracellular ATP in $\mathrm{H}_{2} \mathrm{O}_{2}$ Treated Cells and on the Decrease in Cell Viability and Intracellular ATP Content Induced by 2-DG in HeLa Cells Treatment with $0.1 \mathrm{~mm} \mathrm{H}_{2} \mathrm{O}_{2}$ significantly decreased intracellular ATP content compared with the control group in living cells (Fig. 5A). Co-treatment with $10 \mathrm{~mm}$ PEP and $0.1 \mathrm{~mm}$ $\mathrm{H}_{2} \mathrm{O}_{2}$ produced a significant increase in intracellular ATP contents compared with the $\mathrm{H}_{2} \mathrm{O}_{2}$ alone group. However, no
A

control

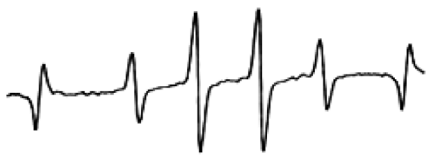

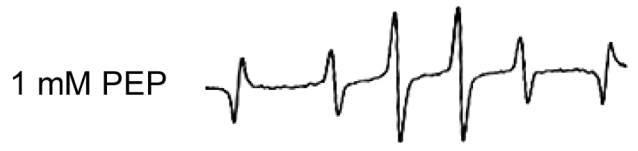

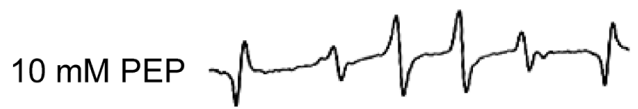

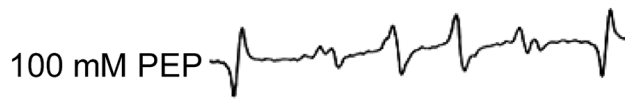

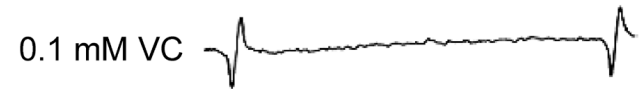

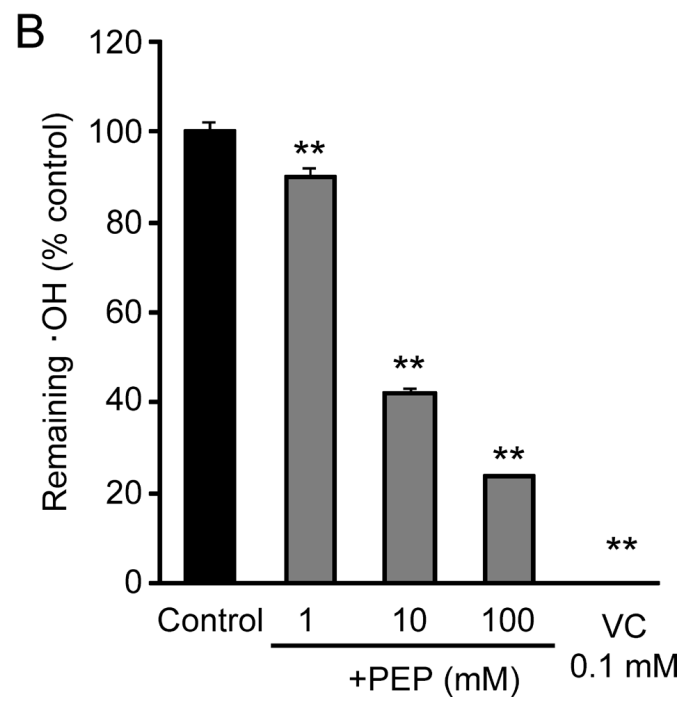

Fig. 3. Hydroxyl Radical (.OH)-Scavenging Activity of PEP

(A) Representative EPR spectrum of DMPO spin adducts of $\cdot \mathrm{OH}$ generated by $\mathrm{H}_{2} \mathrm{O}_{2} / \mathrm{UV}$ radiation. (B) Relative quantification of the anti-oxidant activity of PEP against $\cdot \mathrm{OH}$. Each bar represents mean \pm S.E.M. $(n=4)$. Statistical significance is denoted by ${ }^{* *}(p<0.01$, compared with the control group).

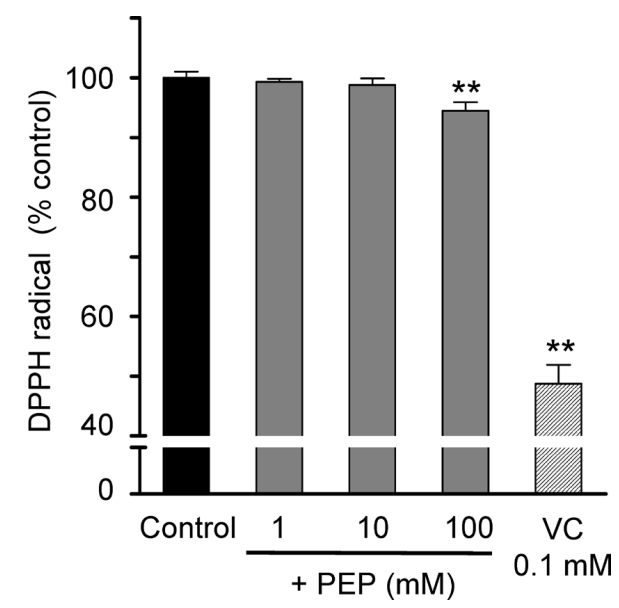

Fig. 4. Scavenging Activity of PEP against DPPH Radical

Each bar represents the mean \pm S.E.M. $(n=4-6)$. Statistical significance is denoted by $* *(p<0.01$ compared with the control group). 
A

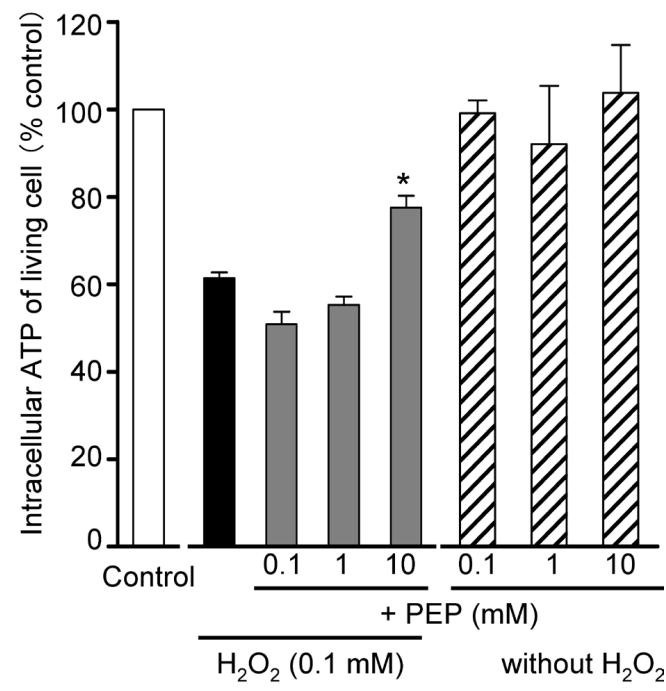

B
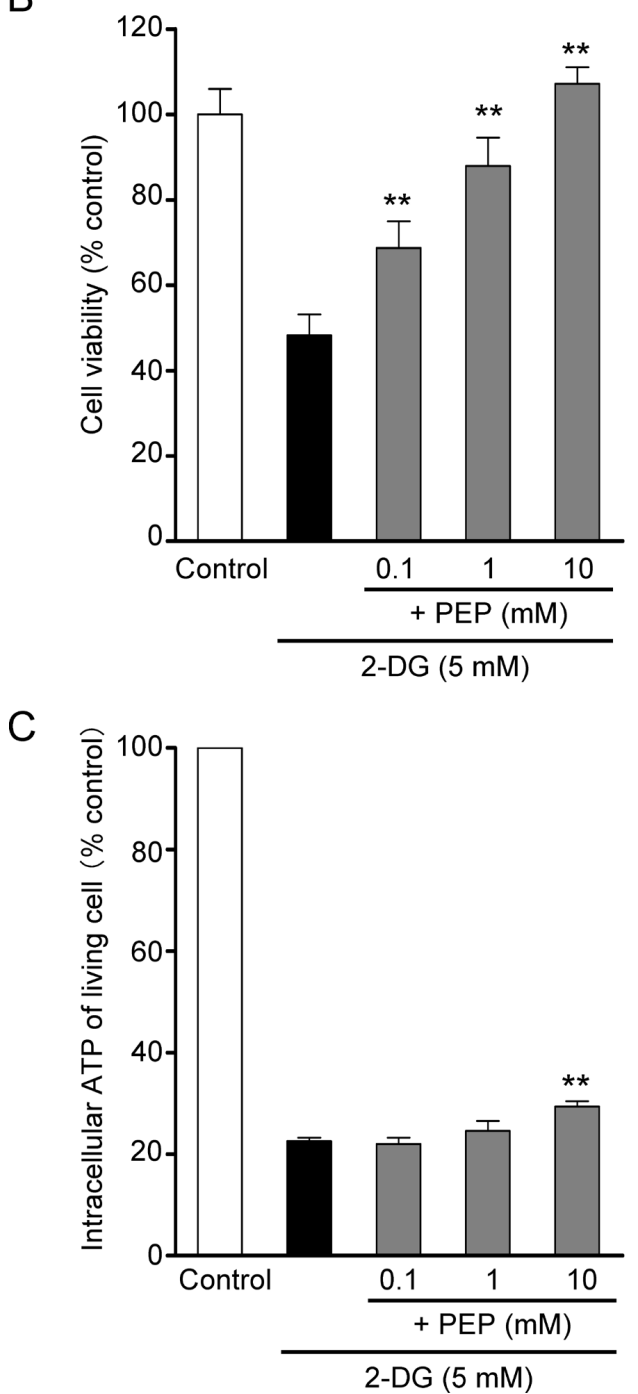

Fig. 5. Effect of PEP on Intracellular ATP and Cell Viability

(A) Effects of PEP on intracellular ATP depression induced by $\mathrm{H}_{2} \mathrm{O}_{2}$ in HeLa cells Effect of PEP on (B) the decrease in cell viability and (C) the decrease in intracellular ATP induced by 2-DG, a glycolysis inhibitor, in HeLa cells. Each bar represents mean \pm S.E.M. $(n=3-8)$. Statistical significance is denoted by $*$ or $* *(p<0.05$ or $p<0.01$, compared with the $\mathrm{H}_{2} \mathrm{O}_{2}$ - or 2-DG-treated groups, respectively). significant effect on ATP content was observed for $0.1-10 \mathrm{~mm}$ PEP in non- $\mathrm{H}_{2} \mathrm{O}_{2}$-treated cells. As shown in Fig. 5B, cell viability was significantly decreased by treatment with $5 \mathrm{~mm}$ 2-DG for $24 \mathrm{~h}$ in serum-free medium compared with the control group $(p<0.01)$. Treatment with $0.1-10 \mathrm{~mm}$ PEP dose-dependently attenuated the decrease in cell viability induced by 2-DG. Treatment with $5 \mathrm{~mm}$ 2-DG also significantly decreased the intracellular ATP content at $12 \mathrm{~h}$ (Fig. 5C); however, only $10 \mathrm{~mm}$ PEP significantly attenuated this decrease, with lower doses having little effect.

\section{DISCUSSION}

In this study, we have demonstrated that PEP, an intermediate of glycolysis, was able to suppress the $\mathrm{H}_{2} \mathrm{O}_{2}$-induced decrease in cell viability and increase in cell injury (evaluated by PI stain) seen in HeLa cells. PEP also inhibited the increase in intracellular ROS in HeLa cells induced by $\mathrm{H}_{2} \mathrm{O}_{2}$ and exhibited scavenging activity against radicals, particularly $\cdot \mathrm{OH}$. These results indicate that PEP protects against cellular injury induced by oxidative stress and these actions, at least in part, may be attributed to anti-oxidative effects.

$\mathrm{H}_{2} \mathrm{O}_{2}$-induced cellular injury in cultured cells has frequently been used as an in vitro model of organ injury associated with oxidative stress, such as ischemic/reperfusion injury. ${ }^{8,14)}$ $\mathrm{H}_{2} \mathrm{O}_{2}$ can penetrate the cellular membrane and be degraded to $\mathrm{OH}$, a potent cellular toxicant, which activates the apoptosis pathway and eventually induces cell injury. The results of this study indicate that PEP has significant scavenging activity against radicals, with particular efficacy against $\cdot \mathrm{OH}$, and suggest that the $\cdot \mathrm{OH}$ scavenging effect plays an important role in the cytoprotective effects of PEP. In contrast, its scavenging activity against the DPPH radical was considerably less potent, and hence such an effect is unlikely to be involved in the cytoprotective effects of PEP. DPPH radical is a long-lived nitrogen radical and is markedly different from the highly reactive oxygen radical species. It is often used to determine the radical-scavenging activity of natural products and food additives. ${ }^{15)}$ However, Huang et al. ${ }^{16)}$ reported that DPPH radical is a stable radical that bears no similarity to the highly reactive and transient peroxy radicals involved in lipid peroxidation. They also found that some anti-oxidants that react quickly with peroxy radicals seem to react slowly or not at all with DPPH radical. Therefore, the feeble effect of PEP against the DPPH radical should not invalidate our conclusions on the anti-oxidative properties of PEP, especially considering its effectiveness in scavenging $\cdot \mathrm{OH}$.

The results of this in vitro study confirm previous in vivo results showing a protective effect afforded by PEP in various animal disease models, ${ }^{1,3-6)}$ and these effects may be exerted, at least in part, through the cytoprotective and antioxidant effects of PEP. Combined with the in vivo and in vitro results, we suggest that administration of PEP may have therapeutic value in treating diseases whose etiology involves ROS. In addition, the results of this study also suggest that PEP may be an endogenous antioxidant substance that helps to maintain the function of cells and organs against unknown pathophysiological threats.

In previous reports, it has been suggested that PEP, which has a high-energy phosphate group, can efficiently supply ATP to, and subsequently protect, organs and cells. ${ }^{1,2,6)}$ ATP 
has many essential roles in the biogenic function of cells, and a decrease in the intracellular ATP level can induce cellular dysfunction and injury through the deterioration of ATPase enzyme activity. In our current study, only a high dose $(10 \mathrm{~mm})$ of PEP was able to block both the decrease in intracellular ATP and cell injury in $\mathrm{H}_{2} \mathrm{O}_{2}$-treated cells. However, lower doses of PEP $(0.1,1 \mathrm{mM})$ showed cytoprotective effects against $\mathrm{H}_{2} \mathrm{O}_{2}$-induced cellular injury without an increase in ATP. These results indicate that attenuation of a decrease in ATP has no or a limited contribution to the cytoprotective effect of PEP. To evaluate the cytoprotective potential of PEP against the cell injury induced by inhibition of glycolytic ATP production, we examined the effects of PEP on cell injury and intracellular ATP reduction in cells treated with 2-DG. PEP also showed significant cytoprotective activity against the cell injury, but did not attenuate the decrease in ATP in 2-DG treated cells. The mechanisms of cell injury induced by 2-DG seem to be related, not only to a reduction in ATP, but also to other factors, including ROS production, ${ }^{17)}$ endoplasmic reticulum stress, ${ }^{18)}$ and cytokine production. ${ }^{19)}$ Furthermore, to evaluate the contribution of the antioxidant activity of PEP against 2-DG in HeLa cells, we measured intracellular ROS production using $\mathrm{CM}-\mathrm{H}_{2} \mathrm{DCFDA}$; however, no significant change in intracellular ROS production was observed (data not shown). Therefore, the antioxidant effects may make a limited contribution to the cytoprotective effect of PEP against 2-DG, or none at all.

In a previous study, we demonstrated that PEP was the only biological substance with a high-energy bond that could penetrate the cell membrane through the anion exchanger. ${ }^{2)}$ However, we did not clarify whether the cytoprotective effect of PEP could be exerted through intracellular or extracellular mechanisms. In addition, we need to determine whether the cytoprotection is exerted by PEP itself or by its metabolites, such as pyruvate, acetyl-CoA, etc. Further studies to examine these points and to clarify the precise mechanisms of the cytoprotective and antioxidant effects of PEP are warranted.

In summary, we have shown that PEP protects HeLa cells against injury by ROS. PEP also showed scavenging potential against radicals, with particular efficacy in eliminating - $\mathrm{OH}$. The results indicate that PEP has cytoprotective effects against oxidative stress-induced cell injury that are at least partly attributable to its anti-oxidative properties. We suggest that PEP is a bifunctional carbohydrate metabolite with cytoprotective and anti-oxidant activity, and has potential for use in the treatment of ROS-related diseases, such as ischemia/ reperfusion-induced injury and acute lung injury.

\section{REFERENCES}

1) Saiki S, Yamaguchi K, Chijiiwa K, Shimizu S, Hamasaki N, Tanaka M. Phosphoenolpyruvate prevents the decline in hepatic ATP and energy charge after ischemia and reperfusion injury in rats. J. Surg. Res., 73, 59-65 (1997).
2) Hamasaki N, Hardjono IS, Minakami S. Transport of phosphoenolpyruvate through the erythrocyte membrane. Biochem. J., 170, 39-46 (1978).

3) Hultman J, Ronquist G, Forsberg JO, Hansson HE. Myocardial energy restoration of ischemic damage by administration of phosphoenolpyruvate during reperfusion. A study in a paracorporeal rat heart model. Eur. Surg. Res., 15, 200-207 (1983).

4) Hickey MJ, Knight KR, Hurley JV, Lepore DA. Phosphoenolpyruvate/adenosine triphosphate enhances post-ischemic survival of skeletal muscle. J. Reconstr. Microsurg., 11, 415-422 (1995).

5) Hojo M, Ito H, Tsuji Y, Ariyoshi A, Hamasaki N. A study of preservation solution containing phosphoenolpyruvate in renal transplantaion. Med. Bull. Fukuoka Univ., 21, 301-310 (1994).

6) Golbidi S, Moriuchi H, Yang C, Irikura M, Irie T, Hamasaki N. Preventive effect of phosphoenolpyruvate on hypoxemia induced by oleic acid in Guinea pigs. Biol. Pharm. Bull., 26, 336-340 (2003).

7) Si K, Liu J, He L, Li X, Gou W, Liu C, Li X. Caulophine protects cardiomyocytes from oxidative and ischemic injury. J. Pharmacol. Sci., 113, 368-377 (2010).

8) Park KM, Kramers C, Vayssier-Taussat M, Chen A, Bonventre JV. Prevention of kidney ischemia/reperfusion-induced functional injury, MAPK and MAPK kinase activation, and inflammation by remote transient ureteral obstruction. J. Biol. Chem., 277, 2040-2049 (2002).

9) Lu Y, Cederbaum AI. CYP2E1 and oxidative liver injury by alcohol. Free Radic. Biol. Med., 44, 723-738 (2008).

10) Miyamoto $Y$, Iwao $Y$, Tasaki $Y$, Sato $K$, Ishima $Y$, Watanabe H, Kadowaki D, Maruyama T, Otagiri M. The uremic solute indoxyl sulfate acts as an antioxidant against superoxide anion radicals under normal-physiological conditions. FEBS Lett., 584, 2816-2820 (2010).

11) Cuzzocrea S, Reiter RJ. Pharmacological action of melatonin in shock, inflammation and ischemia/reperfusion injury. Eur. J. Pharmacol., 426, 1-10 (2001).

12) Yang $C$, Moriuchi $H$, Takase $J$, Ishitsuka $Y$, Irikura $M$, Irie $T$. Oxidative stress in early stage of acute lung injury induced with oleic acid in guinea pigs. Biol. Pharm. Bull., 26, 424-428 (2003).

13) Yang CQ, Ishitsuka Y, Moriuchi $H$, Golbidi S, Jin ZJ, Irikura M, Irie T. Protection afforded by a herbal medicine, Sho-seiryu-to (TJ19), against oleic acid-induced acute lung injury in guinea-pigs. $J$. Pharm. Pharmacol., 61, 925-932 (2009).

14) Harrison R. Structure and function of xanthine oxidoreductase: where are we now? Free Radic. Biol. Med., 33, 774-797 (2002).

15) Magalhães LM, Segundo MA, Reis S, Lima JL. Methodological aspects about in vitro evaluation of antioxidant properties. Anal. Chim. Acta, 613, 1-19 (2008).

16) Huang D, Ou B, Prior RL. The chemistry behind antioxidant capacity assays. J. Agric. Food Chem., 53, 1841-1856 (2005).

17) Wang Q, Liang B, Shirwany NA, Zou MH. 2-Deoxy-D-glucose treatment of endothelial cells induces autophagy by reactive oxygen species-mediated activation of the AMP-activated protein kinase. PLoS ONE, 6, e17234 (2011).

18) Heminger K, Jain V, Kadakia M, Dwarakanath B, Berberich SJ. Altered gene expression induced by ionizing radiation and glycolytic inhibitor 2-deoxy-glucose in a human glioma cell line: implications for radio sensitization. Cancer Biol. Ther., 5, 815-823 (2006).

19) Dréau D, Morton DS, Foster M, Fowler N, Sonnenfeld G. Effects of 2-deoxy-D-glucose administration on cytokine production in BDF1 mice. J. Interferon Cytokine Res., 20, 247-255 (2000). 